\title{
Voice over Internet Protocol (VoIP): UAE Perspective
}

\author{
${ }^{1}$ Tariq Rahim Soomro and ${ }^{2}$ Dawar Asfandyar \\ ${ }^{1}$ College of Engineering and Information Technology, \\ Al-Ain University of Science and Technology, Al-Ain, UAE \\ ${ }^{2}$ Department of Information Technology, Szabist, Dubai Campus, UAE
}

\begin{abstract}
Voice over Internet Protocol (VoIP) is the present and future of telecommunication technology, based on hardware and software enabling users to use the Internet as a medium to communicate. United Arab Emirates (UAE) is federation of seven emirates situated in the southeast of the Arabian Peninsula in Southwest Asia on Persian Gulf. Use of VoIP in UAE is currently restricted. This study is written in keeping in view the advancement of VoIP technology and its economic perspective in all over the world. This study discusses the fact that VoIP legal use in UAE will enhance UAE economy. First study explore the history of VoIP along with its features, services and tools next study will explore world wide economic perspective and role of VoIP during recession period; latter study will focus on survey conducted on use of VoIP and finally conclusion.
\end{abstract}

Key words: VoIP, UAE, economic perspective, communicate, survey, recession

\section{INTRODUCTION}

Voice over Internet Protocol (VoIP)-a revolutionary technology, it is a combination of hardware and software that enables companies, organizations and individual users to use the Internet as a transmission medium for telecommunication. In VoIP both technology and services are involved where the Internet protocol is a technology which is using a common computer network and transmission as a service. The VoIP mechanism is different from the traditional phone system. In VoIP analog audio signals human voice converts into digital signals and then these audio digital data transmitted over the Internet in the form of data packets. The Internet plays a major role as a backbone in VoIP communication system. Following are the key factors which come in favor of VoIP Technology over Public Switched Telephone Network PSTN (Valdes and Roos, 2009):

- Reduce communication cost

- Multiple users

- VoIP-Hardware and software

- Reduced administrative cost

- Improved manageability

- Increased flexibility

United Arab Emirates (UAE) came into existence in 1971 as a result of the unification of seven self-governing sheik-ruled emirates: Abu Dhabi, Ajman, Dubai, Fujairah, Ras al-Khaimah, Sharjah and Umm al-Qaiwain. This
Middle Eastern country is situated in south east of the Arabian Peninsula in Southwest Asia on the Persian Gulf. Although, $90 \%$ of UAE is desert land it is an oil rich country. Peoples from different nationalities e.g., Indian, Pakistanis, Chinese, Bangladeshis European etc are living in United Arab Emirates, some of them are doing business and most of them are doing jobs. The growth of the tourism industry in UAE has been phenomenal over the years and is often regarded as one of the fastest growing tourist destinations. Due to its developed infrastructure, tolerant culture, safe environment, world class hotel and hospitable industry and soothing climate, UAE has attracted both leisure and business travelers across the world (Valdes and Roos, 2009).

In UAE Etisalat and Du are two main telephone and Internet services provider. Currently most of the business users and home users are making international calls either from Etisalat or from Du and VoIP in UAE is legally not allowed. On the other hand it is no denying a fact that the large number of people are still using VoIP from different source like Internet cafes, homes etc. The major use of VoIP in UAE is mostly for cheap international calls through the Internet using software like Skype, SweetCalls, FreeCalls, IntVoIP, VoIPWise, etc., with relatively cheaper rates. Most of the VoIP software use Virtual Private Network (VPN) for example, Hotspot shield, Smart surf, KongShare etc., where these VoIP communication packets can transfer through VPN tunnel and that make it easiest and safer way for making international calls and Etisalat or Du are mostly not able

Corresponding Author: Tariq Rahim Soomro, College of Engineering and Information Technology, 


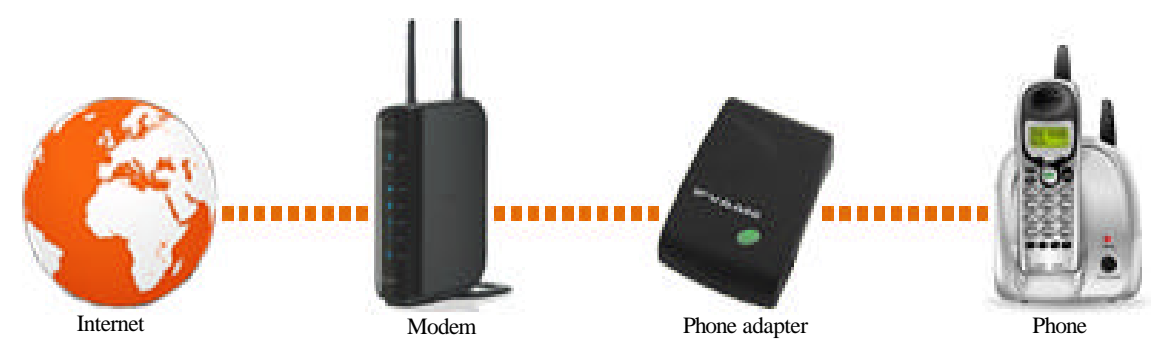

Fig. 1: ATA device, standard Phone and Internet

to chase these kinds of VoIP data packets. Skype and all other major VoIP services are completely blocked in UAE. There are however some ways to get around. User can use a VPN hosted in foreign countries and just connect to that VPN. So effectively all voice call traffic is carried on the VPN server and user can use VoIP from UAE. Etisalat and Du are trying their best to block the known VPN and the new VPN are emerging to facilitate Etisalat and Du users to connect to them and use the VoIP services and this hide and seek game is going on.

This study is written keeping in view the fact that how VoIP legal use will help UAE economy and technically speaking Etisalat and Du has to allow otherwise they can not stop illegal use of VoIP. This study will first explore the history of VoIP along with its features, services and VoIP tools; next this study will explore the economic perspective of VoIP world-wide including UAE perspective and VoIP role during global recession; latter section will focus on the survey results on VoIP usage conducted in UAE; finally conclusion that use of VoIP is technically and economically viable and UAE should go ahead with use of VoIP as soon as possible.

History of VoIP: To precise the history of VoIP, there is need to understand some basic technologies involves in VoIP Communication system i.e., telephone and internet. Mr. Alexander Gram Bell and Elisha Gray invented the telephone instrument in 1870 's and the first regular telephone exchange was established in New Haven in 1878. Early telephones were leased in pairs to subscribers. Earlier telephone user required to connect with one another and subsequently a switch invented which would connect one line to any of 100 lines through Relays and Sliders. This change in the technology allowed calls to be switched digitally and later enabled all manner of automated menus and functionality that eliminated the need for human operators. In 1984 the US government broke apart $\mathrm{AT}$ and $\mathrm{T}$ allowing end users to stop leasing their phones from $\mathrm{AT}$ and $\mathrm{T}$ and allowed them to purchase their own phones. On the other hand the Internet was first developed by ARPANET (Advanced Research Projects Agency NETwork) in 1968 founded by the US Department of Defense in 1957. As the PC became popular, online service companies (e.g., Prodigy and AOL) formed to provide proprietary information and email services. Subscribers would dial into the network with their telephone lines would pay an hourly fee to receive the services offered. In 1989, Tim Berners-Lee and a group of researchers at CERN (an international scientific organization based in Geneva, Switzerland) created Hypertext Transfer Protocol (HTTP) and a text format code called hypertext markup language. They also invented a universal resource identifier (later universal resource locator or URL) to identify document locations. The telephone and the Internet were vital to the existence of VoIP but there is another technology that is closely related and that is called Transmission Control Protocol/ Internet Protocol (TCP/IP) the technical protocol that defines the form of net data packets and how they travel to their destinations was invented by Vint Cerf in 1972 (Hallock, 2004).

During this stage, the groundwork has been documented and VoIP started in February 1995 by a small organization called Vocaltec, Inc. Their product, internet phone allowed one user to call another user via their computers, a microphone and a set of speakers. Latter on in 1998 some entrepreneurs started to market PC-phone and phone to phone VoIP solutions. That time the phone calls were marketed as Free nation-wide long distance call and when the caller would start the call he/she had to listen to advertisements before the call was connected. Another major development in 1998 was the hardware's invasion into the market. By the end of 1998 VoIP calls transactions amounting to $1 \%$ by 2000 , VoIP calls accounted for $3 \%$ and by 2003 that number had jumped up to $25 \%$ (Hallock, 2004).

VoIP framework: The VoIP call can be made in three ways. These three ways connectivity can be distinguished in terms of devices and system requirements (Valdes and Roos, 2009).

Analog Telephone Adaptor (ATA): A device used for converting analog signals into digital signals. A simplest way of connecting a standard phones with ones computer or internet connection for VoIP use as shown in Fig. 1. 


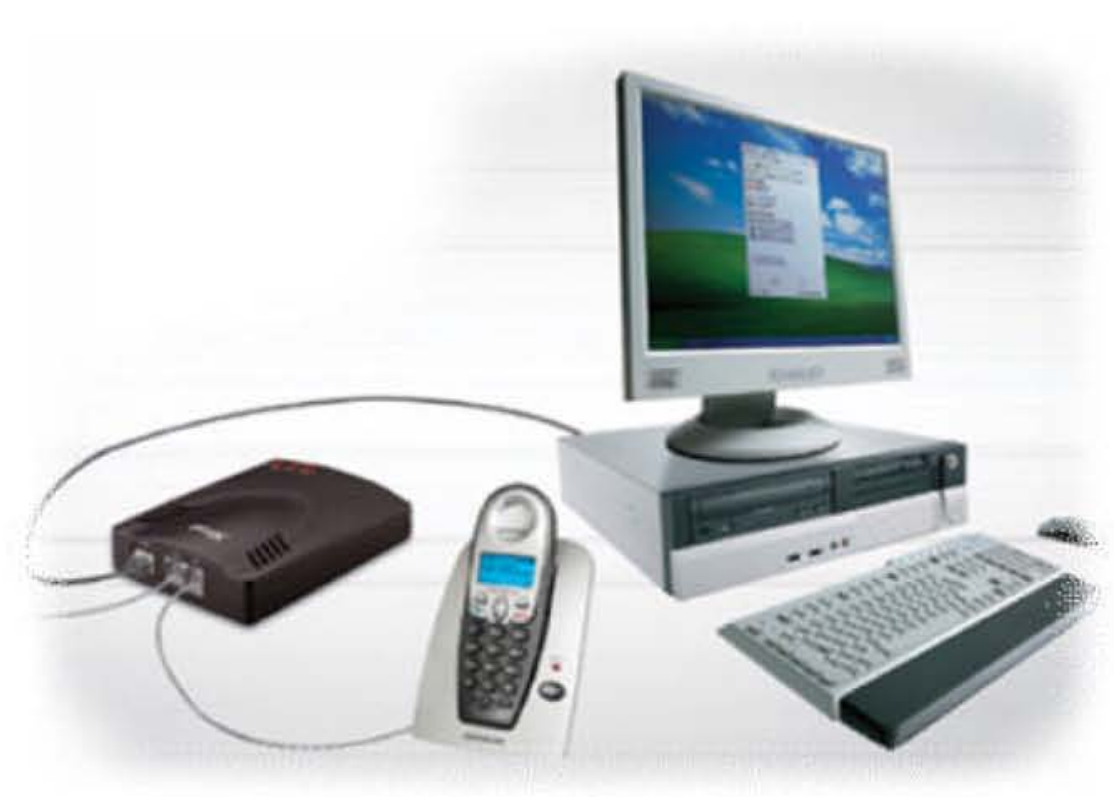

Fig. 2: IP Phones, LAN cable Cat 5e, 6 or 6 e etc. Switch and Internet

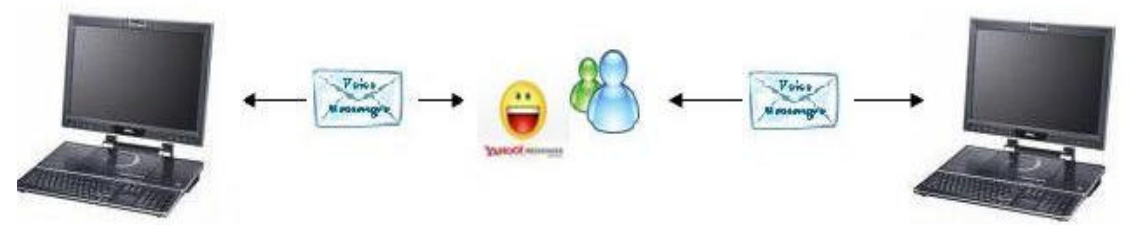

Fig. 3: Software (Yahoo/MSN messenger for Voice Chat. etc.) a microphone, speakers, a sound card and an Internet connection

IP phones: These kind of phones usually used in organizations. These phones have normally RJ-45 connectors which can be easily connect with the Router or network switch just like normal computers or network printers. These IP phones have also IP address which can assign latter after installing the IP Phone system in companies or organizations network so that IP phones data packets can travel through LAN network. It is very much useful for multinational companies who operate in several countries as shown in following Fig. 2.

Computer-computerr: The easiest way in VoIP technology is computer to computer communication. One can get connected through any voice chat software's like Yahoo messenger, MSN messenger or Google-talk which are used as Voice Chat software. Just install these software's and get connect for free. One can also share photos, videos and live web cam through these software. The only thing is required is the Internet connection on both parties as shown in Fig. 3 .
Packet switching: The first question comes to the mind when one talk about VoIP is that how voice data pass from one VoIP device or software to another? The VoIP, actually use packet switching which is the alternative of circuit switching where data will be encapsulated and it will create a packet and that packet will be routed over the Internet to reach their destination point. In VoIP voice data will be sending through the router over the Internet, this process is known as packet switching. Typically a packet contains 1000-1500 bytes in one packet. Also VolP uses VoIP Codec. It is a kind of a computer program and it installed as software on the server or burn within chip of hardware like ATA or IP phone etc. The main function of codec is to convert voice signals into digital and transmitted over the Internet or network during VoIP call (Valdes and Roos, 2009).

VoIP features and services: The VoIP has a bundle of services and features and this section will discuss some of the core feature of VoIP. The biggest service of VoIP is 
that the customers can make calls from anywhere in the world where a broadband Internet connection is available. Some of the important features are:

- Multi-caller

- Anonymous call block

- Caller ID with name

- Extra virtual numbers

- Online account management

- Voicemail

- Telemarketer blocking

- Do not disturb

- Area code selection

- Travel globally

- Return call

- Multi-ring and many other services

VoIP software tools: There are several VoIP software's freely available on the Internet which provides userfriendly features. Some of the most popular VoIP software's are as follows:

Skype: In whole world including UAE the Skype is the most popular software nowadays and currently Skype has $>512$ million registered users (Schonfeld, 2009). The Skype service comes with application software called a softphone. The Skype gives us high quality of voice. PC-PC call is totally free whereas if one wants to call on mobile or landline number then user have to subscribe Skype account with much lower rates as compared to traditional phone system.

Features include video conferencing, SMS, voicemail, call forwarding, contact list, integration with MySpace, public chats, business control panel, sketch pad, desktop sharing and many others.

InterVoIP: InterVoIP also give reasonable calls rates facility over worldwide and just like Skype InterVoIP also gives user online account management facility where user can subscribe and recharge their account. User can easily pay InterVoIP by credit card and other payment machenism e.g., PayPal. InterVoIP is second most popular then Skype in UAE. Features include cheap SMS, cheap PC-phone calls, free PC-PC calls and even very cheap Phone to phone calls and others.

Google talk: It is a free Web-based application for instant messaging and voice over internet protocol (VoIP), offered by Google Inc. Google talk is similar then IntVoIP and Skype-it gives VoIP services with cheap rates. Features include voice mail, chat room, file transferring also available from Google talk software, audio video chat and party chat command are the main features of Google talk.

Vbuzzer: Vbuzzer or Vbuzzer Messenger is a voice over IP (VoIP) and instant messaging software and services. It provides low call rates worldwide and like Skype and IntVoIP user can manage account online. Features include video conferencing, SMS, voicemail, call forwarding, contact list, integration with MySpace, public chats, business control panel, sketch pad, desktop sharing and many others.

Economic perspective of VoIP: For any country's business, industries are important factors to make the country economy strong and better performance of these industries means increase in productivity and revenue. As a result better economy is very important for economical growth.

Normally industries and businesses invest a lot of capital on their infrastructure and the reason behind this investment is for better and smooth performance with minimum effort and to gain maximum benefit. Normally investment comes in following categories which are as follows (Alleman et al., 1994):

\section{- Utilities \\ - Communications \\ - Transportation \\ - Land development}

The ITU (a leading United Nations agency for information and communication technology) issues study of telecommunications and development study states that Telecommunications can increase the efficiency of economic, commercial and administrative activities, improve the effectiveness of social and emergency services and distribute the social, cultural and economic benefits of the process of development by more equitably throughout the country (Alleman et al., 1994).

The VoIP technology not only boosted a country economy as well this new industry has change the communication way of business as a result business communication comes on cheap call rates and improves economy. In general VoIP effect on economy directly and in-directly by three ways:

- Reduce the cost of production

- Increase revenues

- Increase employment 
Asian J. Inform. Technol., 9 (3): 170-178, 2010

\begin{tabular}{|c|c|c|}
\hline Location & 2005 growth revenue & 2009 growth revenue \\
\hline North America & $\$ 2.6$ billion & $\$ 13.3$ billion \\
\hline Europe & $\$ 2.3$ billion & $\$ 12.7$ billion \\
\hline Asia Pacific & $\$ 4.2$ billion & $\$ 12.9$ billion \\
\hline
\end{tabular}

Table 2: Percent of VoIP service revenue coming from residential vs. business customers

\begin{tabular}{lc}
\hline Location & Percentage \\
\hline North America & 51 \\
Europe & 72 \\
Asia Pacific & 83 \\
\hline
\end{tabular}

\section{Table 3: Worldwide VoIP subscriber base}

\begin{tabular}{lc}
\hline Years & $\begin{array}{c}\text { Approximate number of } \\
\text { VoIP subscribers (million) }\end{array}$ \\
\hline 2005 & 19 \\
2006 & 40 \\
2007 & 80 \\
2008 & 130 \\
2010 & 250 \\
\hline
\end{tabular}

Normally those companies whose total business depends on communication system reflect a good output on a country economy in telecommunication sectors. In (Budde, 2008) some valuable facts and figure has been given which shows how VoIP increase the revenue of those countries who adopt VoIP technology in Table 1 and 2 .

VoIP worldwide: Not only VoIP services are increasing revenue but VoIP equipments are also giving a huge revenue and profit which are using in this technology. According to Budde (2008) the VoIP equipments revenue has increase from $\$ 3.95$ billion in 2005-\$11.9billion in 2010 which is a very huge amount. Generally VoIP market covers three user segments:

- Private Branch Exchanges (PBXs) for enterprises

- Infrastructure operated by service providers

- Residential access equipment

At the end of 2005, the PBX segment accounted for $46 \%$ of VoIP equipment revenue while infrastructure and residential gear each took a $27 \%$ share.

Meanwhile, the number of residential VoIP subscribers worldwide is expected to increase to 151.2 million by 2010 , from 15.8 million in 2005 as shown in Fig. 4. According to Budde (2008) the VoIP subscribers from 2005-2008 and estimation of the subscribers in 2010 are shown in follows Table 3.

VoIP comparison: US vs. Europe: The Fig. 5 is showing VoIP subscription comparison between United Sates of America and Europe. Red line indicates European countries statistics and blue line is for US. This clearly

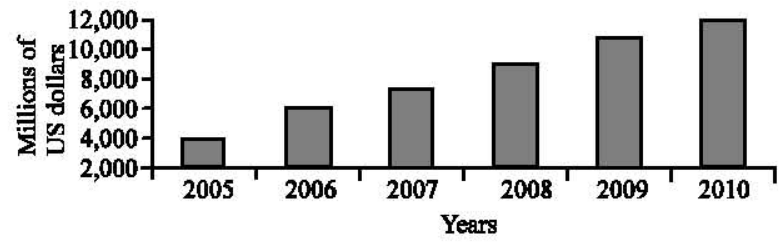

Fig. 4: Worldwide VoIP-enabled equipment revenue forecast (in millions of US dollars)

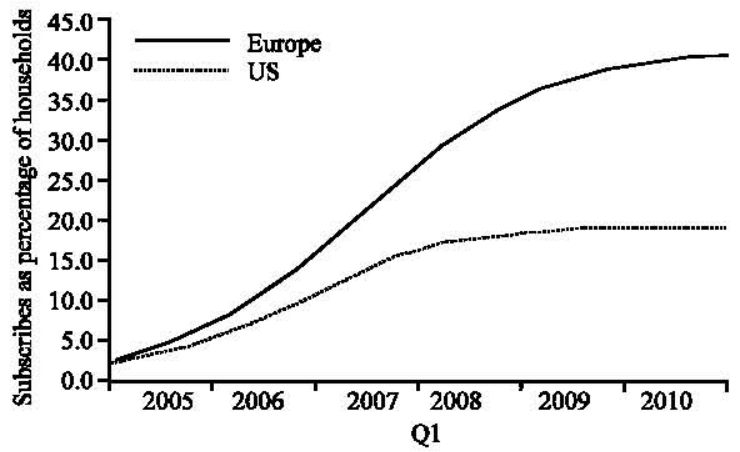

Fig. 5: VoIP subscription comparison between United States of America and Europe

shows that from past 5 years, VoIP subscription growth is high in Europe as compared to United Stated of America

VoIP in Asia: The development of IP-based services and networks across Asia has also built up a strong momentum. The expansion of IP-supporting infrastructure, however has mostly focused on the developed markets and has been heavily dependent on assistance by governments. At the same time, the development of VoIP services leveraging directly off legacy networks has been much more extensive as it has been pushed by numerous telecom operators from a multitude of entrepreneurial operators right through to the slow moving incumbents. China and Japan are two of the key markets in Asia (Budde, 2008).

VoIP in UAE: The UAE's telecommunication market has shown tremendous growth over the recent past. According to PC Mag Midleeast the total size of the UAE IT market is expected to grown from $\$ 3.2$ billion in 2009 to approaching $\$ 4.7$ billionn in 2013. The UAE Internet penetration was estimated to be at $54.3 \%$ by the end of 2008 which was far above the average for the Middle East and North Africa (MENA) region. This highlights UAE's position as one of the most advanced IT countries in the region. The UAE is a regional hub and has excellent 
Asian J. Inform. Technol., 9 (3): 170-178, 2010

\begin{tabular}{lll}
\multicolumn{2}{l}{ Table $4:$ Comparison of VoIP with other industries } \\
\hline Rank & Industry & Growth (\%) \\
\hline 1 & Voice over IP (VoIP) & $179,035.8$ \\
2 & Search engines & 1,655 \\
3 & e-commerce and online auctions & 468.9 \\
4 & Online dating and matchmaking & 248.8 \\
5 & Tank and armored vehicle manufacturing & 244.7 \\
6 & Petrochemical manufacturing & 221.2 \\
7 & Mining support & 186.7 \\
8 & Wireless telecommunications carriers & 183.4 \\
9 & Biotechnology & 182.1 \\
10 & Warehouse clubs and supercenters & 146.5 \\
\hline
\end{tabular}

Table 5: US top 10 biggest recession winners in 2009

\begin{tabular}{llc} 
Rank & Industry & $\begin{array}{c}\text { Revenue growth } \\
2009(\%)\end{array}$ \\
\hline 1 & Voice over internet protocol providers (voIP) & 20.1 \\
2 & Ecommerce and online auctions & 12.6 \\
3 & Biotechnology & 10.3 \\
4 & Engine, turbine and power transmission & \\
& Equipment manufacturing & 10.0 \\
5 & Scheduled bus service & 9.2 \\
6 & Court reporting services & 7.7 \\
7 & Community housing services & 7.5 \\
8 & Search engines & 6.5 \\
9 & Family counseling & 6.1 \\
10 & Video games & 5.8 \\
\hline
\end{tabular}

telecommunication and IT infrastructure and can sever a potential market of almost 2 billion people in surrounding regions including Asia and the Middle East.

VoIP during global recession: Global recession hits all the industries very badly. Many businesses whether small or large comes in the range of global recession which starts from 2009. As a result most of the business completely collapsed and majority is affected badly by global recession.

Due to the reason, the employees in all sectors has lost their jobs and all over the world market also effected. But even in this tough time, VoIP plays an important role in boosting the Country overall Economy and in particular the telecommunication system. According to IBIS World which is the most trusted independent source for market research, shows that during 2000-2009 VoIP was the best industry as compared to others industries as shown in Table 4. In the same context this research report is providing some valuable data which is showing that VoIP industry is the winner of Global recession during 2009 as shown in Table 5.

VoIP users survey: To get the opinion of public and businesses two separate survey were conducted to examine the necessity of VoIP technology for public and business use. The result shows that VoIP technology is the essential need for all kind of users in all over the United Arab Emirates for making using cheap and reliable telecom utilization. The survey was conducted by using manual questionnaire form and also an electronic

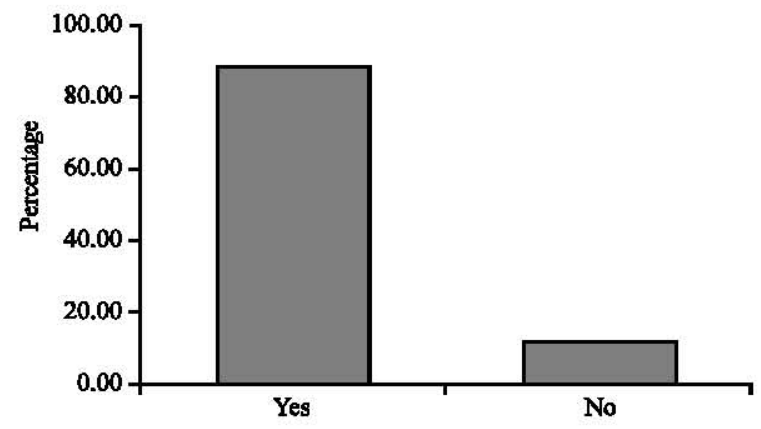

Fig. 6: Componies response about VoIP technology

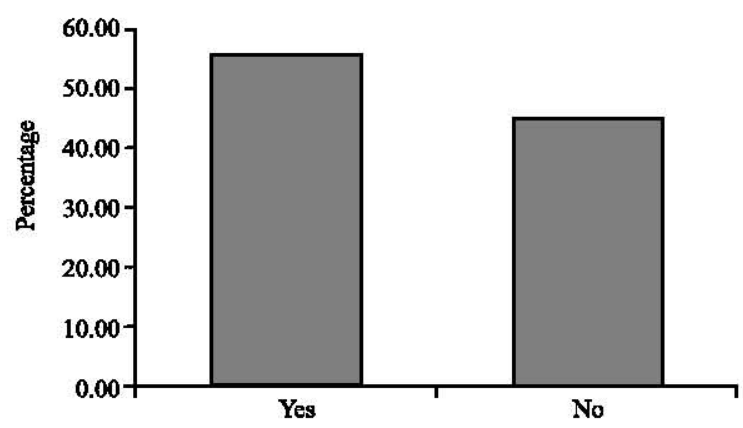

Fig. 7: Rate of the use of VoIP technology

questionnaire form was developed to collect data. Following are some of the important finding of the result of surveys in graphical form.

Business users-survey: This survey has been collected from multiple sectors government, private for example; including Dubai Customs, United Bank Limited and few other companies from different categories like building materials, logistics, IT organizations, etc.

Total online users: 9

Survey link: http://www.esurveyspro.com/Survey.asp $\mathrm{x} ? \mathrm{id}=\mathrm{a} 01367 \mathrm{~d} 7-\mathrm{b} 07 \mathrm{e}-4178-\mathrm{ae} 34-68 \mathrm{~b} 387662359$.

Question 1: Are you familiar with VoIP technology? Figure 6 is showing that about $83 \%$ companies are well awere about VoIP technology, its use and its benefit etc.

Question 2: Do your organization use VoIP Technology? Figure 7 is demonstrating that about $56 \%$ of the companies are using VoIP technology from different sources. Like free VoIP software's and tools. It's also showing that $45 \%$ of the business users are not using VoIP technology. 


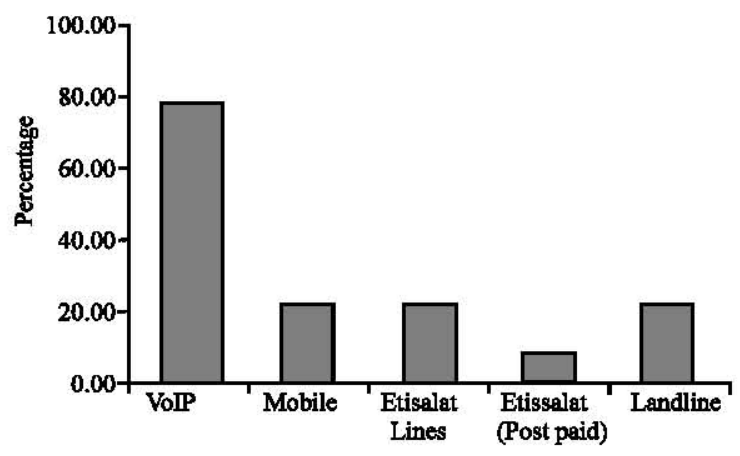

Fig. 8: Percentage of the usres for the use of VoIP for international calls

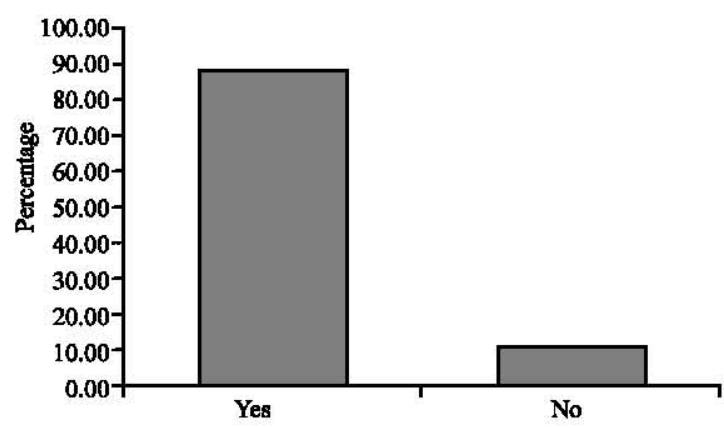

Fig. 9: Normal VoIP and business communication

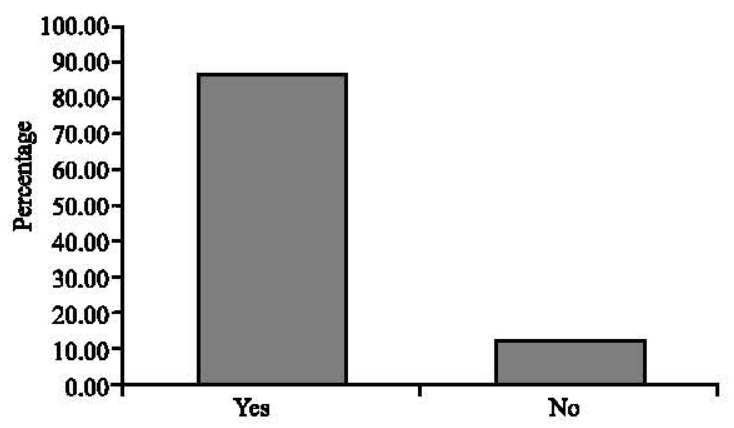

Fig. 10: VoIP is essential tool in UAE business

Question 3: How you are making international calls? Figure 8 is showing the source of making international calls, VoIP is using about $79 \%$ for making international calls and others are using Etisalat, landline or post and pre paid.

Question 4: Do you think that VoIP can enhance your business communication in term of quality, security, ease of use and installation? Figure 9 is showing that about $88 \%$ of business users are agree that VoIP can enhance business communication services and about $10 \%$ users are not agree with this answer.

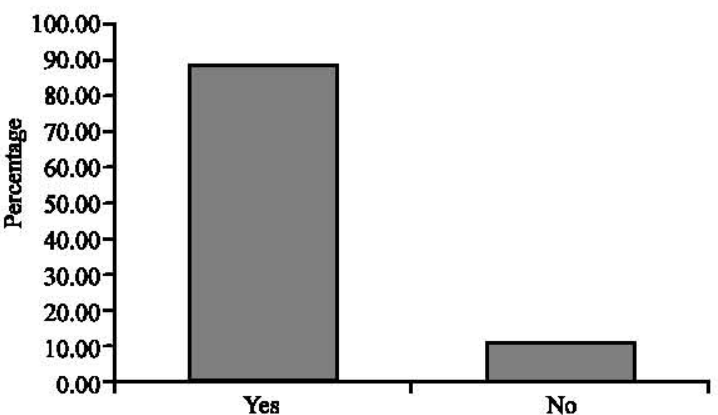

Fig. 11: VoIP is basic and necessary need for cheap telecommunication

Question 5: Do you think that VoIP technology is essential need for home and Business use in United Arab Emirates? Figure 10 is showing that about $90 \%$ of the business users are sure that VoIP is an essential tool in U.A.E for business purpose only about $10 \%$ users are not agree with this answer.

Question 6: Do you think that VoIP service should be legalized by Etisalat/du in United Arab Emirates? Figure 11 is showing that about $90.00 \%$ business users want that VoIP is the basic and necessary need for cheap telecommunication system for there business user where the companies can save lots of money in the crucial time of financial crisis in all over the world.

Individual user based-survey: This report has also conducted VoIP survey from individual users, for example office workers, drivers, accountants, office boys etc., this part of the report clearly shows that VoIP technology is also a major requirement for the expatriates in all over the UAE.

Total online users: 45 users.

Total manual survey users: 16 users

Survey link: http://www.esurveyspro.com/Survey.as px?id=77cd9280-1ba8-477b-8773-c69105f98b88.

Question 7: How many times you make international calls in a week? Figure 12 is showing that about $40 \%$ users are making international calls on daily basis $30 \%$ users are making calls once in a week, $12 \%$ users are making calls twice in a week whereas about $19 \%$ users are making calls frequently.

Question 8: How you make international calls? Figure 13 is showing that Users are making international calls from different resources i.e., $26 \%$ are using Etisalat, $16 \%$ are 


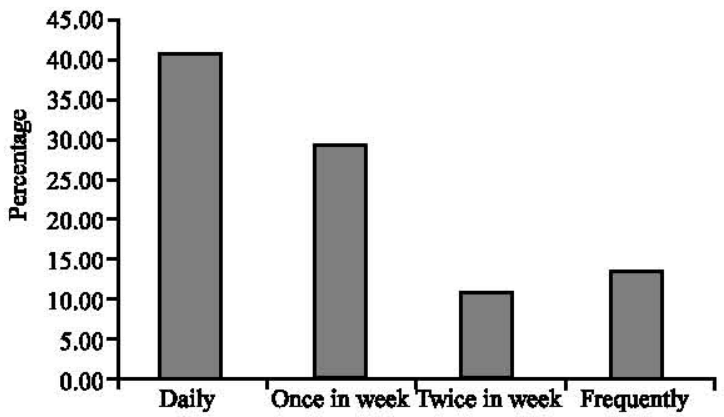

Fig. 12: Users and daily international calls

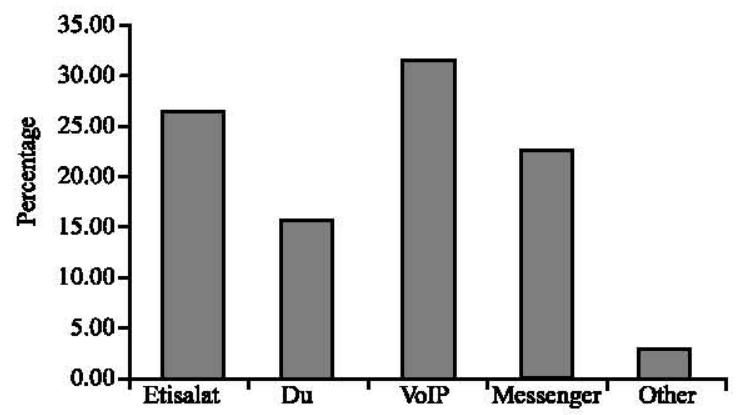

Fig. 13: Users and international calls from different resources

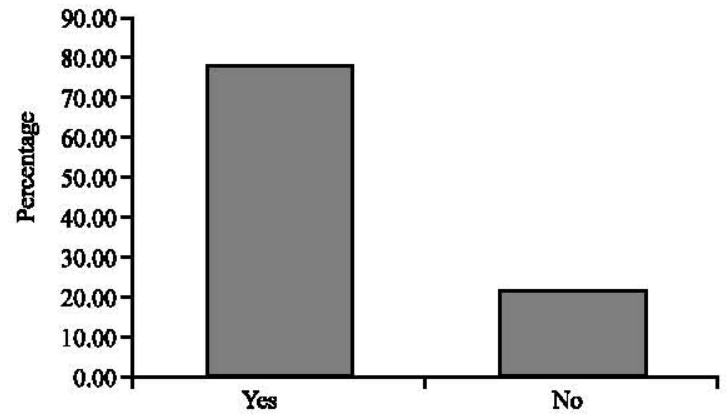

Fig. 14: Percentage of the users who are familiar with VoIP technology

using du about 33\% users are using VoIP technology, $24 \%$ users are using messengers like Yahoo and MSN for voice calls and other are using other sources.

Question 9: Are you familiar with VoIP technology Means internet calling cards? Figure 14 is showing that about $80 \%$ users are aware from VoIP technology, its benefits and its use only $20 \%$ users don't know about this technology.

Question 10: Do you think that VoIP calling calls are cheap and reliable source for international calls? Figure 15 is showing that $97 \%$ of the users are agreed

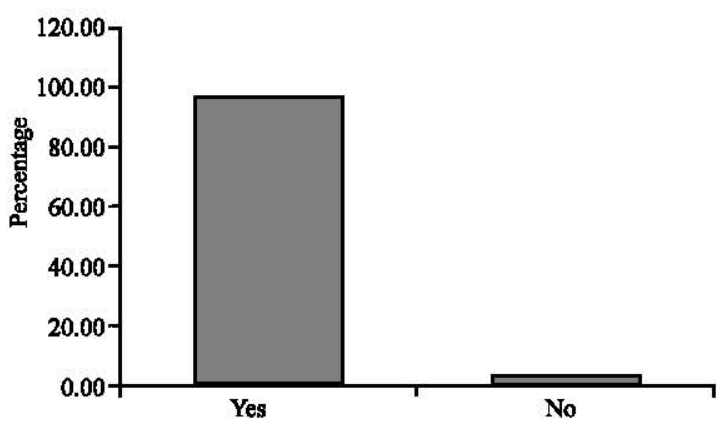

Fig. 15: VoIP as a cheap and reliable source of communication

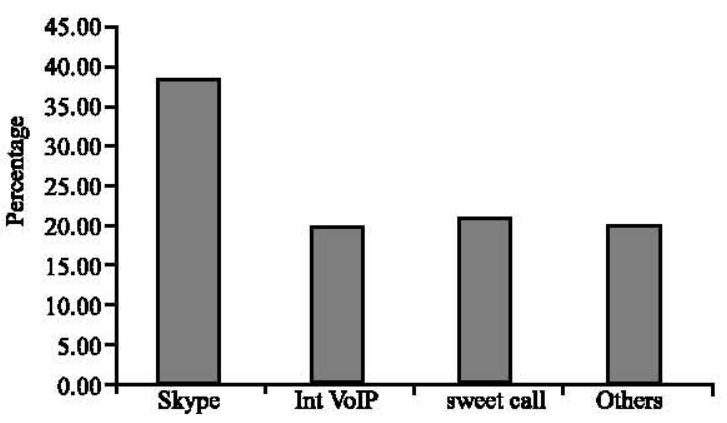

Fig. 16: The use of different VoIP software

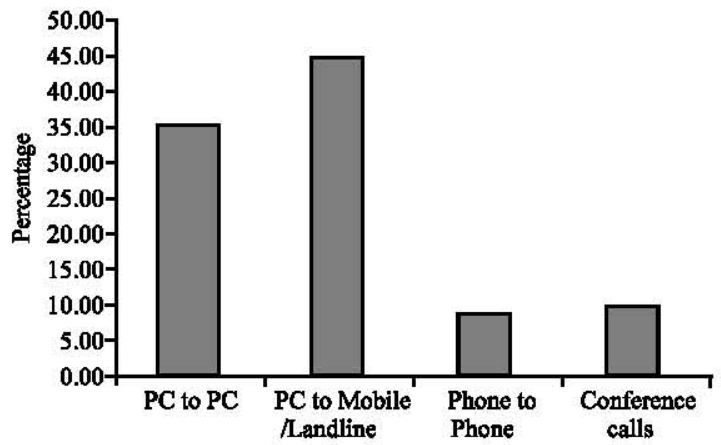

Fig. 17: Utilization of VoIP technology for different purpose

that VoIP is a cheap and a reliable source of communication only $3 \%$ users are not agreed with this statement.

Question 11: Which VoIP software you are using for international calls? Figure 16 is showing that users are using Skype which is 38 and $20 \%$.

IntVoIP, $22 \%$ are using Sweetcalls and $20 \%$ users are making international call from other resources like messengers etc.

Question 12: How you make VoIP calls? Figure 17 is showing that $45 \%$ users are using VoIP technology for PC 


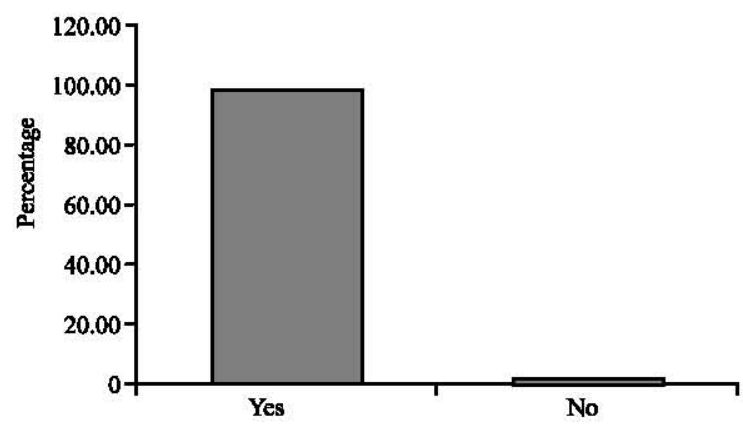

Fig. 18: Response to the legalization of VoIP technology

to mobile or landline numbers, $\mathrm{PC}$ to $\mathrm{PC}$ is using $35 \%$ whereas $10 \%$ users are using for conference calls and around $10 \%$ users are using for Phon to phone.

Question 13: Do you want VoIP service to be legalized by Etisalat/du in United Arab Emirates? Figure 18 is showing that about $97 \%$ users are agred and $5 \%$ users are not agreed with this answer. Majority of the users want that VoIP is the basic and necessary need for cheap telecommunication system for there use where they can save lots of money in the crucial time of financial crisis in all over the world.

\section{CONCLUSION}

The results in survey shows that users in UAE are using VoIP services directly or indirectly without the knowledge of Etisalat or Du and if VoIP will be legalized more and more users will join this pool to fully utilize this service and it will also trigger to boost the economy of UAE. The VoIP is the technology of present and future and this research eager to prove that using and allowing VoIP technology is good idea technically and economically. Users of Etisalat and Du are in need of this technology and economically VoIP uses will boost the growth of country's economic condition. During this research work on 15th March 2010, Etisalat has finally decided to provide its business customers with reliable and secure VoIP solutions, a door which has been opened by the legalization of the service by the UAE Telecommunications Regulatory Authority. Still VoIP is not legalized to use by individual users. TRA has to look into this matter also and also plan to launch VoIP for individual users which will of course add more and more users to VoIP pool and that will obviously cause to get big boost in UAE economy as VoIP is not a looser technology, it is gainer for all.

\section{REFERENCES}

Alleman, J., C. Hunt, D. Michaels, M. Mueller, P. Rappoport and L. Taylor, 1994. Telecommunications and economic development: Empirical evidence from Southern Africa. Proceedings of the 10th Biennial International Telecommunications Society Meeting, International Telecommunications Society, Sydney.

Budde, P., 2008. Global-VoIP-Overview and Statistics. Paul Budde Communication Pty Ltd, Tanzania.

Hallock, J., 2004. A brief history of VoIP. Evolution and Trends in Digital Media Technologies-COM 538, Masters of Communication in Digital MediaUniversity of Washington, http://www.joehallock. com/edu/pdfs/Hallock___VoIP_Past.pdf.

Schonfeld, E., 2009. Skype hits 521 million users and $\$ 185$ million in quarterly revenue. TechCrunch. http://techcrunch.com/2009/10/21/skype-hits-521million-users-and-185-million-in-quarterly-revenue/.

Valdes, R. and D. Roos, 2009. How VoIP worksintroduction retrieved. http://communication.howstuffworks.com/ip-telephony.htm. 